\title{
Experimental Investigations on Emission Characteristics of Dual Fuel Mode Diesel Engine
}

\author{
${ }^{1}$ Dr. P. Vara Prasad, ${ }^{2}$ V. Mallikarjuna \\ ${ }^{1}$ Principal, Srinivasa Institute of Technology and Science, Kadapa, AP, India, \\ ${ }^{2}$ Asst. Prof., Department of Mechanical Engineering, AITS, Rajampet, AP, India, \\ 1pvpd1969@gmail.com, ${ }^{2}$ mallikarjunav83@gmail.com
}

\begin{abstract}
Diesel engines are highly efficient and rugged due to their high compression ratios and are widely used in transportation and agricultural sectors. The main disadvantages of diesel engines are that they emit higher particulate matter and NOx emissions. The ever increasing cost of crude petroleum products and strict regulation norms laid down on tailpipe emissions has necessitated search for suitable alternative and renewable fuels for diesel engines to operate in dual fuel mode. In the present work KME20 (20\% karanja methyl ester - $80 \%$ high speed diesel) and Bio-CNG (enriched biogas) are selected as fuels to operate the diesel engine on dual fuel mode $(\mathrm{DFM})$ at $0.3 \mathrm{~kg} / \mathrm{h}, 0.6 \mathrm{~kg} / \mathrm{h}$ and $0.9 \mathrm{~kg} / \mathrm{h}$ flow rates of biogas. In this study it is found that the thermal efficiency (BTE), NOx and Smoke emissions are lower, CO and HC emissions are higher for dual fuel mode diesel engine when compared to diesel engine normal operation.
\end{abstract}

Keywords - Bio-CNG, Dual Fuel, Diesel Engine, KME20, Emissions

\section{INTRODUCTION}

The global concern for air pollution and depletion of ozone layer has forced to re-evaluate the use of conventional fuels like gasoline, diesel and coal as well. Now, the search for non derivative of petroleum fuels to IC engines is essential to continue to meet the demand of growing energy demands of the future. The current conventional energy sources are depleting in nature with the global oil resources expected to be adequate to meet the demand of energy up to 2030 which is projected by world energy outlooks IEA. Energy consumption to be considered as a sign of index of economic growth and social development [1-3], further gross domestic products (GDP) and per capita income, is now considered as a measure of economic development of any country [4]. Due to two oil shocks during 1970s, the energy self-sufficiency was considered to be fundamental and a key driver for new and renewable energy programs in the country [5].

Biogas is a renewable alternative gaseous fuel and is derived from raw biogas. The raw biogas is principally a mixture of methane $\left(\mathrm{CH}_{4}\right)$ and carbon dioxide $\left(\mathrm{CO}_{2}\right)$ along with little amount of other trace gases such $\mathrm{asH}_{2} \mathrm{~S}$ and water vapor. It is produced from the sources of cow dung, non-edible seed cakes, animal waste, food waste, agricultural waste, municipal waste etc., by anaerobic digestion. The biogas production becomes an attractive source for earning of extra income for many farmers in the rural areas across in India.
Usually, gaseous fuels have long been known to be used in many large stationary engines and as one of dual fuel in different proportions in combination of liquid fuel. The dual fuel mode diesel engine operated effectively on combination of gaseous fuel and liquid fuel. The air and gaseous fuel mixture gets compressed during compression process in cylinder and liquid fuel (pilot fuel) injected into the cylinder just before the end of compression stroke through a conventional fuel injection system for ignition of compressed charge.

Some of the investigations found that the diesel engine performance slightly reduced along with higher emissions for biodiesel operation [11]. The NOx emissions of diesel and biodiesel are reduced by retarded injection timing [12]. It was examined that the performance and environmental aspects of diesel engine fuelled with neat biodiesel and its blends. The biodiesel operation showed slight reduction in performance, higher SFC, lower $\mathrm{CO}$ emissions and higher $\mathrm{NO}_{\mathrm{X}}$ emissions [13].The effect of injection timing and pressure on the performance characteristics of direct injection diesel engine operated with MhOME (Marotti oil methyl ester) and its diesel blends. 20\% Marotti oil biodiesel-diesel blend produced higher BTE, lower specific fuel consumption and lower exhaust gas emissions amongst the blend ratios considered [14]. Methyl Ester of Sal Oil (SOME) fuelled diesel engine shown that the $\mathrm{CO}, \mathrm{HC}$ and $\mathrm{NO}_{\mathrm{x}}$ emissions were less, with comparable brake thermal efficiency [15]. Brake thermal efficiency was lower for dual-fuel mode engine 
operation than those of diesel operation upto medium load (torque) conditions [10]. For dual fuel mode operation with $0.9 \mathrm{~kg} / \mathrm{h}$ biogas flow rate, the BSFC increased by $36 \%$ and $6.2 \%$ drop in BTE while $\mathrm{CO}$ and $\mathrm{HC}$ emissions increased by $17 \%$ and $30 \%$ and $\mathrm{NO}, \mathrm{CO}_{2}$ and smoke emissions reduction by $39 \%, 42 \%$ and $49 \%$ respectively, in comparison with diesel fuel normal operation, at full load condition[11]. In some studies, the performance characteristics of a dual fuel mode diesel engine using raw biogas, shown that the BTEs to be $20.04 \%, 18.25 \%$, $17.07 \%$ and $16.42 \%$ at compression ratios $18,17,17.5$ and 16 , respectively in dual fuel mode operation where as it was $27.76 \%$ for diesel operation, at full load. And also, an average reduction in $\mathrm{CO}$ and $\mathrm{HC}$ by $26.22 \%$ and $41.97 \%$ while $\mathrm{NOx}$ and $\mathrm{CO}_{2}$ emission increased by $66.65 \%$ and $27.18 \%$ respectively for compression ratio in the range of 16-18 in dual fuel mode operation test.

In the present study, evaluating the performance of diesel engine fuelled with KME20 fuel and dual fuel mode at different flow rates of Bio-CNG. The engine operating at $26^{\circ}$ bTDC (advanced injection timing) and 230bar (fuel injection pressure). The diesel engine performance parameters such as BTE and emissions such as $\mathrm{CO}, \mathrm{HC}$ and oxides of nitrogen $\left(\mathrm{NO}_{\mathrm{x}}\right)$ are measured at all test conditions.

\section{MATERIALS AND METHODOLOGY}

\section{A. Test Fuels}

The test fuels are diesel (HD), KME20 and BioCNG (enriched biogas). In dual fuel mode operation, KME20 used as pilot fuel which acts as the source of ignition and the biogas is used as primary fuel. The properties are presented in table 1 and 2.

Table 1. Properties of diesel and methyl esters of karanja oil

\begin{tabular}{|l|c|c|c|}
\hline \multicolumn{1}{|c|}{ Properties } & HD & KME & $\begin{array}{c}\text { ASTM } \\
\text { D6751-02 }\end{array}$ \\
\hline Viscosity @ $40^{0} \mathrm{C}(\mathrm{cSt})$ & 2.62 & 4.41 & $1.9-6$ \\
\hline Flash point ${ }^{0} \mathrm{C}$ & 55 & 168 & $>120$ \\
\hline Calorific Value in kJ $/ \mathrm{kg}$ & 43000 & 37980 & - \\
\hline Density kg / ${ }^{3}$ & 840 & 881 & $<1000$ \\
\hline Cetane Index & $45-55$ & 50.8 & $>49$ \\
\hline
\end{tabular}

Table 2 Properties of Biogas

\begin{tabular}{|l|c|}
\hline \multicolumn{1}{|c|}{ Properties } & Biogas \\
\hline Relative density $\left(\mathrm{kg} / \mathrm{m}^{3}\right)$ at $\left.1 \mathrm{~atm} . \& 15^{0} \mathrm{C}\right)$ & 0.75 \\
\hline Flash Point $\left({ }^{0} \mathrm{C}\right)$ & 130 \\
\hline Octane Number & $>100$ \\
\hline Flame Speed $(\mathrm{cm} / \mathrm{s})$ & 32.1 \\
\hline Net Energy Content $(\mathrm{MJ} / \mathrm{kg})$ & 36.54 \\
\hline Auto Ignition Temperature $\left({ }^{0} \mathrm{C}\right)$ & $550-600$ \\
\hline Stoichiometric $\mathrm{A} / \mathrm{F}(\mathrm{kg}$ of air $/ \mathrm{kg}$ of fuel $)$ & 16.5 \\
\hline Flammability limits(Vol.\% in air) & - \\
\hline $\mathrm{CH}_{4}(\%$ vol.) & 88 \\
\hline $\mathrm{CO}_{2}$ (\%vol.) & 11 \\
\hline
\end{tabular}

Table 3. Specifications of Test Engine

\begin{tabular}{ll}
\hline Item & Details \\
\hline Make & $\begin{array}{l}\text { Kirloskar TV1, Single cylinder, four } \\
\text { stroke DI diesel engine(naturally } \\
\text { aspirated) }\end{array}$ \\
200 bar \\
Injector opening pressure & $5.2 \mathrm{~kW}$ (7 HP) @1500 RPM \\
Rated power & $87.5 \mathrm{~mm}$ \\
Cylinder Bore & $110 \mathrm{~mm}$ \\
Stroke length & $17.5: 1$ \\
Compression ratio & $23^{\circ} \mathrm{bTDC}$ \\
Standard Injection & \\
Timing(SIT) & \\
\hline
\end{tabular}

\section{B. Experimental Setup}

The test engine is a single-cylinder, four stroke, and direct injection compression ignition (CI) engine. The detailed specifications and dimensions of an engine are shown in Table 3. The present study setup of the dual-fuel engine consists of test engine, eddy current dynamometer, exhaust gas analyzer and the biogas fuel supply system which is shown in Fig.1.

In the present work studied the effect of variation of Biogas (Bio-CNG) flow rates on the performance of dual fuel mode engine with KME20 fuel injected at the best fuel injection timing of $26^{\circ}$ bTDC and fuel injection pressure of 230bar for improving dual fuel mode (DFM) engine performance. The DFM diesel engine was operated on natural induction with basic geometry ( $3 \mathrm{~mm}$ hole). The test set-up equipped with all necessary arrangements and all other instrumentation used is shown in Fig.2

\section{RESULTS AND DISCUSSION}

\section{A. Brake Thermal Efficiency}

Fig. 2 represents the variation of BTE with load at different flow rates of Biogas induction with KME20 fuel.BTE increases with load on dual fuel mode operation. Due to higher viscosity, lower heating value of the injected methyl ester fuel and lower heating value of Biogas results in lower brake thermal efficiency of the engine.

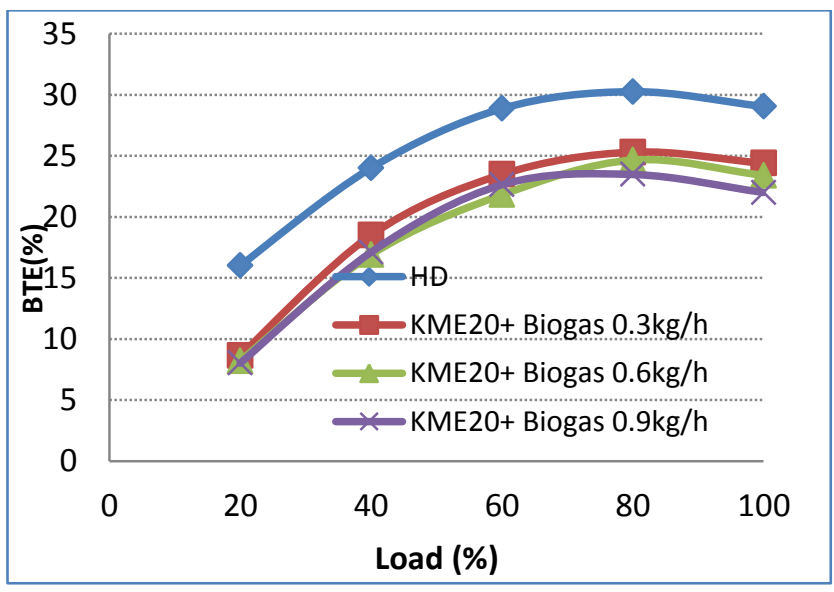

Fig. 2 BTE variations with load for KME+ Biogas 


\section{B. HC Emissions}

Fig. 3 shows the variation of $\mathrm{HC}$ with load for different flow rates of Biogas with KME20 fuel. HC emissions are found to be higher throughout the load spectrum when compared to diesel fuel normal operation. At lower loads, the $\mathrm{HC}$ emissions are high due to slow combustion as engine combustion chamber temperature is low in dual fuel mode operation. The HC emissions decrease as load increases up to $40 \%$ and then increases at further

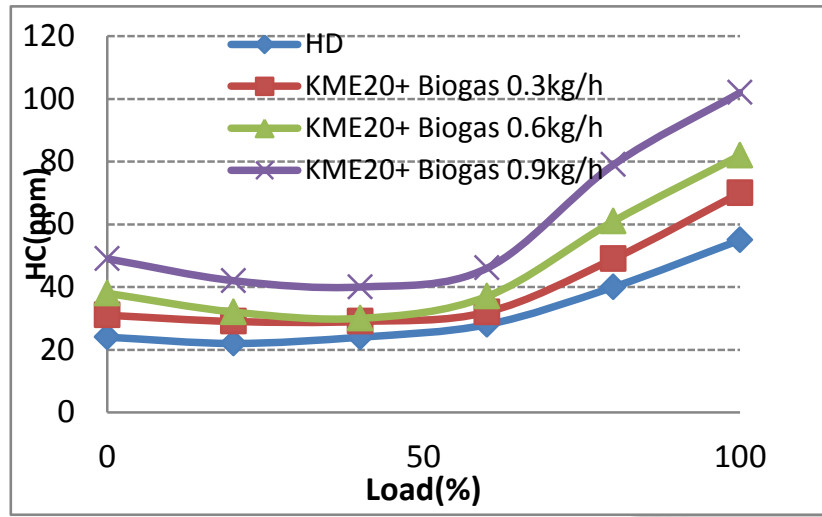

Fig. 3 Variation of $\mathrm{HC}$ with Biogas+ KME20

loads. HC emission values are noted as 49ppm, 61ppm and $79 \mathrm{ppm}$ for KME20 fuel for Bio-CNG flow rates $0.3 \mathrm{~kg} / \mathrm{h}$, $0.6 \mathrm{~kg} / \mathrm{h}$ and $0.9 \mathrm{~kg} / \mathrm{h}$ respectively, where as it is $40 \mathrm{ppm}$ for HD fuel normal operation, at $80 \%$ of full load.

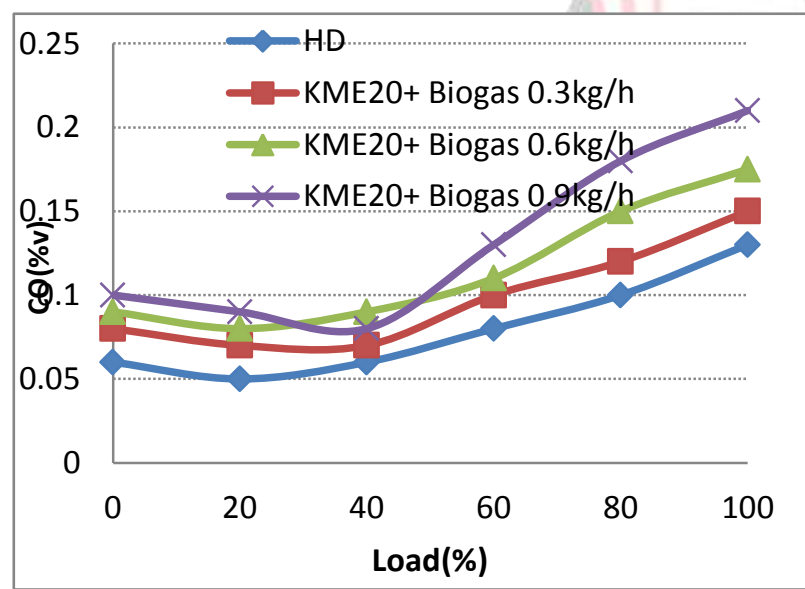

Fig. 4. Variation of $\mathrm{CO}$ emissions with respect to load

\section{CO Emissions}

Figure 4 depicts the variation of $\mathrm{CO}$ with respect to load for different flow rates of Biogas. The $\mathrm{CO}$ emissions are higher at lower loads and then decrease up to medium load, and again increase upto full load. The $\mathrm{CO}$ emissions are found to be $0.12 \%$ vol., $0.15 \%$ vol. and $0.18 \%$ vol. for KME20 dual-fuel operation with $0.3 \mathrm{~kg} / \mathrm{h}, 0.6 \mathrm{~kg} / \mathrm{h}$ and 0.9 $\mathrm{kg} / \mathrm{h}$ flow rate of Bio-CNG induction respectively, where as it is $0.1 \%$ vol. for HD fuel normal operation at $80 \%$ load.

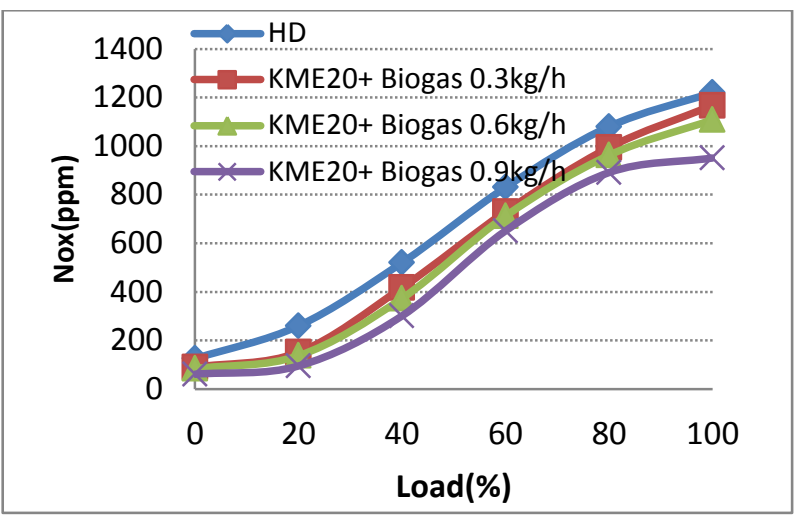

Fig. 5 Variation of NOx with Biogas+ KME20

\section{Oxides of Nitrogen Emissions}

Figure 5 represents the variation of $\mathrm{NO}_{\mathrm{x}}$ emissions for different flow rates of Biogas with KME20 fuel. $\mathrm{NO}_{\mathrm{x}}$ emissions are mainly composed of $\mathrm{NO}$ and less quantity of $\mathrm{NO}_{2}$. The $\mathrm{NO}_{\mathrm{x}}$ emissions are increased with load as more amount of fuel needs to be injected with load which resulting in increases cylinder combustion gas temperature. However, the $\mathrm{NO}_{\mathrm{x}}$ emissions in the dual fuel mode operation are lower when compared to the diesel (HD) fuel normal mode. The $\mathrm{NO}_{\mathrm{x}}$ emissions are found to be $994 \mathrm{ppm}, 962 \mathrm{ppm}$ and $891 \mathrm{ppm}$ for KME20 fuel with $0.3 \mathrm{~kg} / \mathrm{h}, \quad 0.6 \mathrm{~kg} / \mathrm{h}$ and $0.9 \mathrm{~kg} / \mathrm{h}$ Biogas flow rates respectively, where as it is $1080 \mathrm{ppm}$ for diesel normal operation at $80 \%$ of full load.

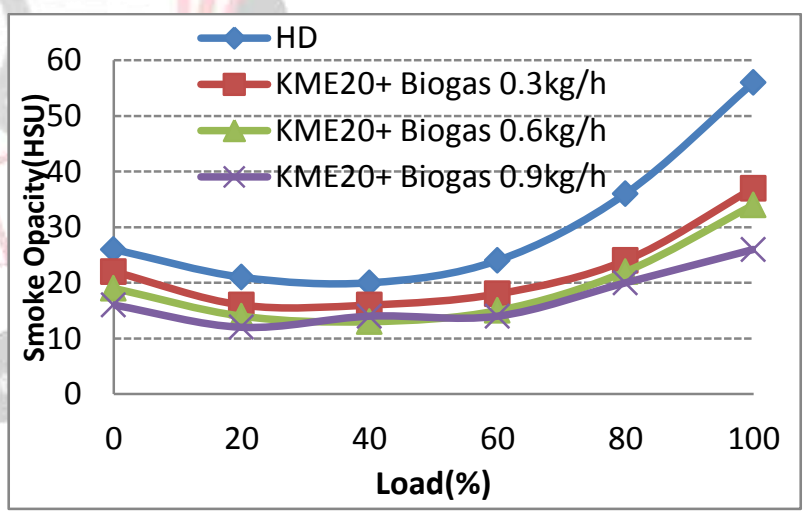

Fig.6 Variation of Smoke with Biogas+ KME20

\section{E. Smoke Emissions}

From the Fig. 6 the smoke opacity is lower for dual fuel operation than that of diesel fuel normal operation. The smoke opacities are 24HSU, 23HSU and $20 \mathrm{HSU}$ for KME20 fuel with Biogas flow rates of $0.3 \mathrm{~kg} / \mathrm{h}, 0.6 \mathrm{~kg} / \mathrm{h}$, and $0.9 \mathrm{~kg} / \mathrm{h}$ respectively, where as it is $40 \mathrm{HSU}$ for diesel fuel normal operation, at $80 \%$ of full load.

\section{CONCLUSION}

In the present study the tests are carried out on dual fuel mode naturally aspirated diesel engine. The investigations conclusion is drawn at $0.6 \mathrm{~kg} / \mathrm{h}$ Biogas flow rate at $80 \%$ load operation. 
- The BTE value for Biogas with KME20 fuel is found to be $25.09 \%$.

- The HC emissions for Biogas with KME20 fuel is noted as $61 \mathrm{ppm}$.

- $\mathrm{CO}$ emissions are found to be $0.15 \%$ vol.for Biogas with KME20 fuel.

- The NOx emissions for Biogas with KME20 fuel is identified as $962 \mathrm{ppm}$

- The smoke emissions for Biogas with KME20 fuel is 23 HSU.

The results showed that the dual fuel engine operation exhibited lower NOx and Smoke emissions, higher HC and $\mathrm{CO}$ emissions at $0.6 \mathrm{~kg} / \mathrm{h}$ flow rate of Biogas. The best results are obtained at $0.6 \mathrm{~kg} / \mathrm{h}$ flow rate of Biogas with KME20 fuel and for smooth engine operation.

\section{REFERENCES}

[1] http://en.wikipedia.org/wiki/Petroleum\#Consumption _statistics.

[2] Agarwal A.K., (2007) Biofuels (alcohols and biodiesel) applications as fuels for internal combustion engines, Progress in Energy and Combustion Science. Vol.33 pp.233-271.

[3] Kjarstad J, Johnsson F, (2010)Resources and future supply of oil, Energy Policy.vol.37 pp.441-64.

[4] Banapurmath N.R., Tewari P.G., (2010) Performance, combustion, and emissions characteristics of a singlecylinder compression ignition engine operated on ethanol-biodiesel blended fuels, Proc. IMechE, Part A: J. Power and Energy. Vol.224 pp.533-543. of a dual fuel diesel engine run on raw biogas-Energy Conversion and Management.87 pp.1000-1009.

[10] Sundarpandian S., Devaradjane G.,(2007) Theoretical and experimental investigation of the performance of vegetable-oil-operated CI engine, SAEPaper No. 2007-32-0067.

[11] Roy M.M., (2009) Effect of fuel injection timing and injection pressure on combustion and odorous emissions in DI diesel engine, Journal of Energy Resources Technology, ASME Transactions.131pp.18 .

[12] Papagiannakis R.G., Hountalas D.T., Rakopoulos C.D., (2007) Theoretical study of the effects of pilot fuel quantity and its injection timing on the performance and emissions of a dual fuel diesel engine, Energy Conversion and Management. 48 pp.2951-2961.

[13] Carraretto C., Macor A., Mirandola A., Stoppato A., Tonon S., (2004) Biodiesel as alternative fuel: Experimental analysis and energetic evaluations, Energy.vol.29 pp.2195-2211.

[14] Banapurmath N.R., Tewrai P.G., Vinodkumar V., (2009) combustion and emission characteristics of DI compression ignition engine when operated on Marotti oil methyl ester and its blends Marotti oil methyl ester with diesel, Sustainable Engineering.2(3)pp. 192 -200.

[15] Vedaraman $=$ N., Puhan S., Nagarajan G., Ramabrahman B.V., Velappan K.C., (2012) Methyl ester of Sal oil (Shorea robusta) as a substitute to diesel fuel-A study on its preparation, performance and emissions in direct injection diesel engine, Industrial Crops and Products. Vol.36 pp.282-288.

[5] World Energy Outlook 2012, IEA publications. pp. 17.

[6] Hiremath R.B., Bimlesh Kumar, Balachandra P., Ravindranath N.H., Raghunandan B.N., (2009) Decentralized renewable energy: Scope, relevance and applications in the Indian context, Energy for Sustainable Development. pp.134-10.

[7] Tint Tint Kywe, Mya Mya Oo, (2009) Production of Biodiesel from Jatropha Oil (Jatropha curcas) in Pilot Plant, World Academy of Science, Engineering and Technology. pp. 6477- 483.

[8] Debabrata Barik, Murugan S., (2014) Investigation on combustion performance and emission characteristics of a DI (direct injection) diesel engine fueled with biogas-diesel in dual fuel mode. Energy.72 pp.760771.

[9] Bhaskor J. Bora, Ujjwal K. Saha, Soumya Chatterjee, Vijay Veer . (2014) Effect of compression ratio on performance, combustion and emission characteristics 